Original article

\title{
Neural activity during the viewing of emotional pictures in veterans with pathological anger and aggression
}

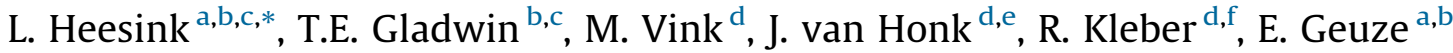 \\ ${ }^{a}$ University medical center, Utrecht, The Netherlands \\ ${ }^{\mathrm{b}}$ Research center military mental health care, Utrecht, The Netherlands \\ ${ }^{\mathrm{C}}$ University of Chichester, Chichester, United Kingdom \\ ${ }^{\mathrm{d}}$ Utrecht university, Utrecht, The Netherlands \\ e University of Cape Town, Cape Town, South Africa \\ ${ }^{\mathrm{f}}$ Foundation Arq, Diemen, The Netherlands
}

\section{A R T I C L E I N F O}

\section{Article history:}

Received 5 May 2017

Received in revised form 15 August 2017

Accepted 5 September 2017

Available online 22 September 2017

\section{Keywords:}

Anger

Aggression

fMRI

Emotional stimuli

Functional connectivity

Attention

\begin{abstract}
A B S T R A C T
Anger and aggression are common mental health problems after military deployment. Anger and aggression have been associated with abnormalities in subcortical and cortical levels of the brain and their connectivity. Here, we tested brain activation during the processing of emotional stimuli in military veterans with and without anger and aggression problems. Thirty military veterans with anger and aggression problems and 29 veterans without a psychiatric diagnosis (all males) participated in this study. During an fMRI scan 32 negative, 32 positive and 32 neutral pictures from the International Affective Picture System were presented in intermixed order. The Aggression group showed heightened activity in brain areas including the supplementary motor area, the cingulum and the parietal cortex, in response to stimuli, regardless of category. Furthermore, the Aggression group showed stronger connectivity between the dorsal anterior cingulate cortex (dACC) and the amygdala during the viewing of negative stimuli, and weaker connectivity between dACC and medial prefrontal cortex during the viewing of positive stimuli. Veterans with anger and aggression problems showed enhanced brain response to all stimuli during the task, irrespective of valence and they rated the pictures more likely as negative. We take this to indicate enhanced preparation for action and attention to the presentation of stimuli that could prove to be threatening. Further, group differences in functional connectivity involving the dACC reveal abnormal processing of stimuli with negative and positive valence. In sum, the results point towards a bias towards an enhanced sensitivity to perceived or potential threat in aggression.
\end{abstract}

(c) 2017 Elsevier Masson SAS. All rights reserved.

\section{Introduction}

Millitary deployment is often a stressful period and regularly leads to mental and social difficulties after homecoming [1]. Frequently occurring problems, besides symptoms of posttraumatic stress disorder and depression, are anger and aggression [2,3]. Emotional and behavioral manifestations of these problems can be very disabling for the individual as well as their surroundings [4]. Problems regarding anger and aggression occur in many psychiatric disorders, the current study therefore takes a transdiagnostic approach [5,6]. Anger and aggression problems have been linked to disturbed emotional processing [7]. Stimuli are more easily

\footnotetext{
* Corresponding author. Department of psychiatry, UMC Utrecht, Heidelberglaan 100, 3584 CX Utrecht, The Netherlands.

E-mail address: liekeheesink@gmail.com (L. Heesink).
}

perceived as negative or threatening, which might lead to reactive or impulsive aggression.

An important brain area in emotional processing is the amygdala [8,9]. The amygdala consists of distinct subnuclei $[9,10]$. The basolateral amygdala (BLA) plays a role in differentiating responses to stimuli currently evaluated to have biologically significant outcomes [11-13]. The BLA is reciprocally connected with a wide range of brain areas, including medial and orbitofrontal prefrontal cortex and has projections to the central medial amygdala (CMA). The CMA in turn projects to areas such as the hypothalamus and brainstem, including the periaqueductal gray, thereby activating appropriate physiological responses such as freezing [14].

In patients diagnosed with Intermittent Explosive Disorder (IED) hyperactivity of the amygdala has been reported in response to angry faces $[15,16]$. Furthermore, the circuitry of the amygdala, 
including the orbitofrontal cortex and the anterior cingulate cortex, has been implicated in disorders characterized by aggressive behavior such as IED and borderline personality disorder $[7,17,18]$.

Post-traumatic stress disorder (PTSD) is a common mental disorder after deployment and also associated with aggression $[19,20]$. Although in PTSD no evidence was found for amygdala dysfunction in relation to general, non-facial, emotional stimuli [21], it was found that patients with PTSD who did not respond to therapy show heightened amygdala activation to such stimuli before treatment [22]. Furthermore, stronger activation in the dorsal anterior cingulate cortex (ACC) is implicated in the processing of negative emotional stimuli in PTSD [21]. Increased attention to negative emotions has been related to dACC activity [23] and might therefore be of interest in aggression as well.

Differences in the processing of emotional stimuli in anger and aggression are mostly tested using facial stimuli $[15,16]$, but general non-facial negative emotional stimuli also elicit amygdala activation [24]. However, whether such stimuli also result in enhanced responses in the amygdala related to anger and aggression is not yet known. Therefore, it is important to investigate the neural response to emotional stimuli in anger and aggression.

Here, we investigate brain responses to general, non-facial, emotional stimuli, in military veterans with and without anger and aggression problems. To this aim, 28 military veterans with anger and aggression problems and 28 veterans without a psychiatric diagnosis (all males) rated 32 negative, 32 positive and 32 neutral pictures from the IAPS while being scanned with fMRI. We studied both brain activity and the connectivity of the amygdala and the dACC with other areas of the brain in relation to the task. Based on previous studies in patients with aggressive behavior, we hypothesize that amygdala and dACC activation will be higher in the impulsive aggression group during the viewing of negative emotional pictures, in comparison to the control group. We expected that the functioning of the amygdala and dACC connectivity is also disturbed in aggression.

\section{Methods}

\subsection{Participants}

In this study, 30 male veterans with anger and aggression problems were included (Aggression group). They were recruited via their psychologists/psychiatrists at the Military Mental Health Care Institute and via advertisements in the waiting room and newsletters for veterans. Additionally, 29 male control veterans without anger and aggression problems were also included. It was attempted to include participants in the control group such that this group did not differ on age, education and number of deployments. These participants were recruited by advertisements in magazines for veterans or had participated in previous studies. Inclusion criteria for the Aggression group were based on the four research criteria for impulsive aggression described by Coccaro (2012):

- verbal or physical aggression towards other people occurring at least twice weekly on average for one month; or three episodes of physical assault over a one year period;

- the degree of aggressiveness is grossly out of proportion;

- the aggressive behaviour is impulsive (not premeditated);

- the aggressive behaviour causes either distress in the individual or impairment in occupational or interpersonal functioning (Coccaro, 2012 [25]).

Inclusion criteria for the Control group were:

- no current DSM-IV diagnosis;

- no history of pathologic aggressive behaviour.
The Ethics Committee of the University Medical Center Utrecht, The Netherlands, approved this study and all participants signed an informed consent before participation after having received a complete written and verbal explanation of the study. This study was carried out in accordance with the Declaration of Helsinki.

\subsection{Interview and questionnaires}

The Dutch version of the International Neuropsychiatric Interview (MINI) was used in order to screen for the presence of comorbid psychiatric disorders [26]. The complete MINI was administered. In this interview the following current or life-time disorders were screened: depressive disorder, dysthymia, suicidal risk, (hypo)manic disorder, panic disorder, anxiety disorder, agoraphobia, social phobia, obsessive compulsive disorder, PTSD, alcohol or drug dependence and/or abuse, psychotic disorders, anorexia nervosa, bulimia nervosa, generalized anxiety disorder, antisocial personality disorder, somatization disorder, hypochondria, body dysmorphic disorder, pain disorder, attention deficit hyperactivity disorder (ADHD) and adjustment disorder. The interview was carried out by the research staff (psychologists with psychodiagnostic expertise).

To measure anger and aggression, the Dutch version of the State-Trait Anger Expression Inventory-revised (STAXI-2; Hovens, Rodenburg, \& Lievaart, 2015, Spielberger, 1999 [27,28]) was used. The STAXI-2 consists of 57 items on a 4-point Likert scale and is divided into two subscales: State Anger and Trait Anger.

Furthermore, the Dutch translation of the Buss-Perry Aggression Questionnaire (AQ) $[29,30]$ was administered. The AQ consists of 29 items on a 5-point Likert scale and is divided into 4 subscales: Physical Aggression, Verbal Aggression, Anger and Hostility.

\subsection{Task}

The task (Van Rooij et al., 2015; Vink, Derks, Hoogendam, Hillegers, \& Kahn, 2014 [21,31]) consisted of 96 pictures from the IAPS [32]. These pictures elicit general emotional experience [32]. The pictures were categorized as neutral, positive, or negative based on the IAPS rating. The pictures were presented for 2 seconds, after which an evaluation screen was presented. By pressing a button with the thumb of their right hand, participants could give their rating (positive, negative or neutral) of the picture within 2 seconds. Immediately after giving the rating, a fixation cross appeared for the remaining trial duration. The task consisted of four blocks, each with 24 pictures in pseudo-randomized order ( 8 neutral, 8 positive, 8 negative). Between the blocks, a fixation cross was presented for 32 seconds. For a schematic overview of the task, see Fig. 1.

\subsection{MRI acquisition}

A 3.0-T whole-body magnetic resonance imaging scanner (Philips Medical System, The Netherlands) was used to acquire the functional images during the task, and a T1 weighted image for within-subject registration. An EPI-SENSE sequence scan acquired 322 functional images during the task, with the following parameters: repetition time $(\mathrm{TR})=1600 \mathrm{~ms}$; echo time $(\mathrm{TE})=23 \mathrm{~ms}$; flip angle $=72.5^{\circ} ; 64 \times 51$ matrix; $4 \mathrm{~mm}$ slice thickness; field of view $($ FOV $)=256 \times 204 \mathrm{~mm}$. For within subject registration, a T1 weighted image was used $(200$ slices, $\mathrm{TR}=10 \mathrm{~ms}$; $\mathrm{TE}=3.8 \mathrm{~ms} ;$ flip angle $=8^{\circ} ; \mathrm{FOV}=240 \times 240 \times 160 \mathrm{~mm}$ ).

\subsection{Preprocessing}

Preprocessing and analyzing the data was done using SPM 12 (http://www.fil.ion.ucl.ac.uk/spm) and hiro3, a Matlab tool for 

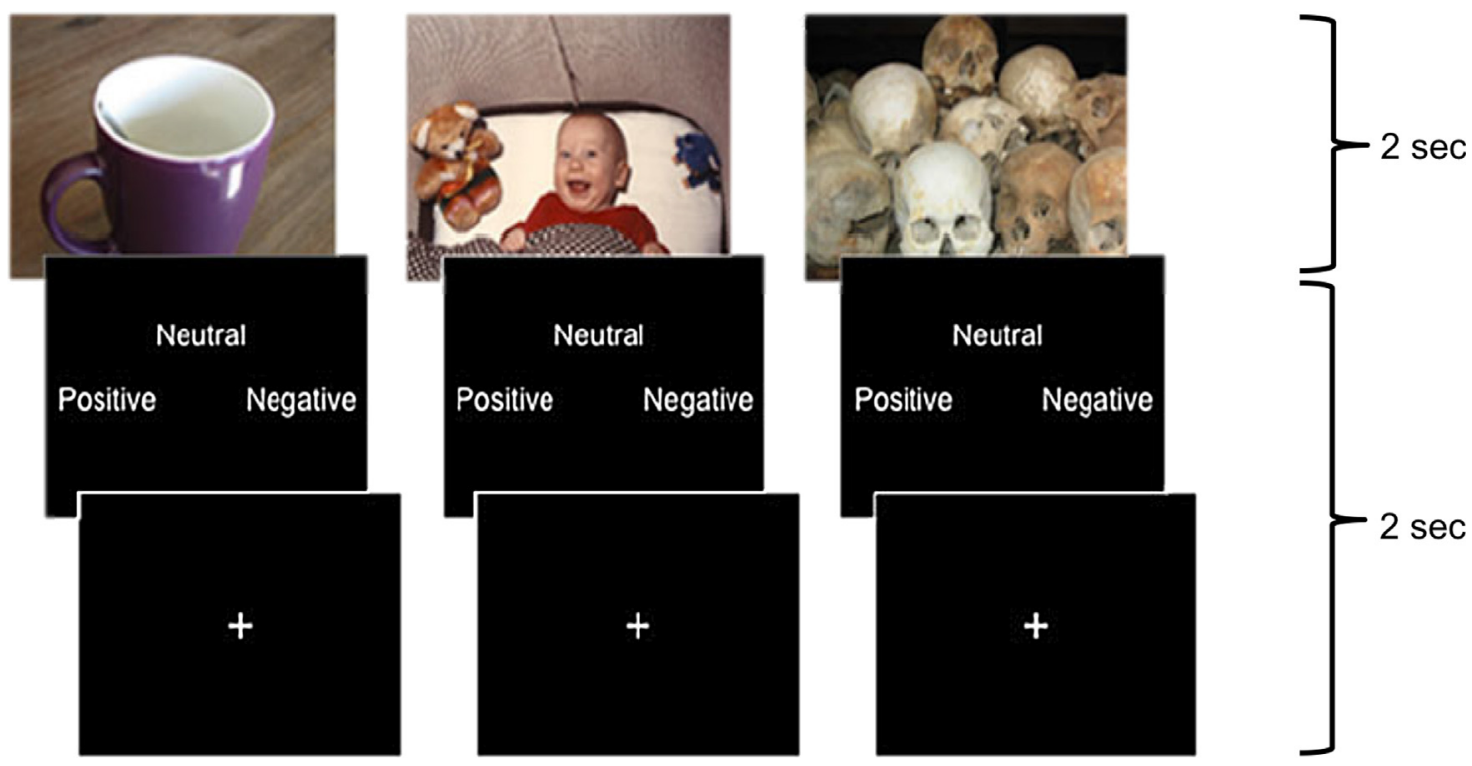

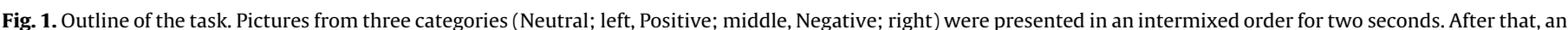

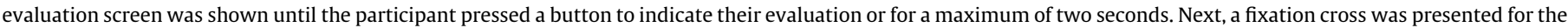
remaining duration of the trial.

visualizing and analyzing fMRI data [33]. Volumes were slice-time corrected to the middle slice and realigned to the first acquired volume. The data were spatially normalized to an MNI T1weighted template. Smoothing was done using an 8-mm fullwidth-at-half-maximum (FWHM) Gaussian kernel.

\subsection{Data analyses}

FMRI data were analyzed using a general linear model regression analysis. Trials were only included when the participants rated the picture congruent to the IAPS rating. For each participant, first-level analyses were performed with the predictors: Neutral stimulus (2 $\mathrm{s}$ boxcar), Positive stimulus $(2 \mathrm{~s}$ boxcar), Negative stimulus ( $2 \mathrm{~s}$ boxcar), response (stick function) and motion parameters. The used contrasts were Negative minus Neutral and Positive minus Neutral stimulus presentation. Further, overall activation due to stimulus presentation was tested, contrasting all stimuli against the implicit baseline. A whole-brain corrected threshold was used such that the family-wise error rate was controlled at 5\%; that is, the chance of any voxel showing a false positive was $5 \%$.

In order to investigate differences in amygdala activation during the viewing of emotional pictures, an ROI analysis was performed. The CMA and BLA were defined based on the probabilistic cytoarchitectonic areas from the SPM anatomy toolbox [34]. When the probability of a certain voxel was higher for the CMA than for the BLA, it was included in the CMA-map and vice versa. The dACC was defined based on the WFU Pick atlas, by using Brodmann's area 32. The same ROI's were used in psychophysiological interaction (PPI) analyses [35]. In the first analyses, familywise error rate correction was again used. However, after failing to find effects strong enough to survive this correction, exploratory analyses were added in order to show weaker but possibly informative effects. The used threshold was $P<.001$, uncorrected, with an extent of $k \geq 20$ voxels [36]. As has been pointed out before [33,36,37], this heuristic measure does not (and does not claim to) provide whole-brain corrected results. In order to at least provide an indication of the level of whole-brain significance, permutation tests were used to acquire the nullhypothesis distribution of cluster extents over the chosen threshold.

\section{Results}

\subsection{Demographics}

Demographic information is depicted in Table 1 . The groups did not differ on age, education and number of deployments. The Aggression group scored significantly higher on all anger and aggression measures.

\subsection{Behavioral data}

Table 2 shows the results of the ANOVA. After analysing the behavioural data of the task, two participants in the Aggression group and 1 participant in the Control group were excluded because they rated too few trials congruently (i.e., according to the IAPS-rating) to include them in the analyses. The Aggression group rated significantly more pictures incongruently to the IAPS rating compared to the Control group for both the Positive $\left(F(1,56)=10.21, P<.01\right.$, partial $\left.\eta^{2}=.16\right)$ and the Neutral picture categories $\left(F(1,56)=5.43, P<.05\right.$, partial $\left.\eta^{2}=.09\right)$. The Aggression group rated the neutral pictures more often as negative $\left(F(1,56)=10.11, P<.01\right.$, partial $\left.\eta^{2}=16\right)$, and the positive pictures more often as neutral $\left(F(1,56)=5.93, P<.05\right.$, partial $\left.\eta^{2}=.10\right)$ and negative $\left(F(1,56)=6.37, P<.05\right.$, partial $\left.\eta^{2}=.11\right)$.

\section{3. fMRI results}

\subsubsection{Task effect}

Brain areas involved in emotional processing were activated by the task, in both the Negative minus Neutral contrast and the Positive minus Neutral contrast, see Table 3 and Fig. 2. For the Negative minus Neutral contrast and the Positive minus Neutral contrast, these regions included the amygdala, hippocampus and orbitofrontal cortex.

\subsubsection{Whole brain group differences}

The whole brain analyses revealed no differences between the two groups on the Negative minus Neutral contrast or the Positive minus Neutral contrast. However, whole brain group differences were found in activation due to stimulus presentation in general, regardless of the valence of the stimuli. Among other regions, 
Table 1

Description of the Anger group and the Control group.

\begin{tabular}{|c|c|c|c|}
\hline & $\begin{array}{l}\text { Anger group }(n=28) \\
\text { Mean }(S D)\end{array}$ & $\begin{array}{l}\text { Control group }(n=28) \\
\text { Mean }(\mathrm{SD})\end{array}$ & Statistics \\
\hline Age & $36.29(6.43)$ & $34.21(7.75)$ & ns \\
\hline Education & $4.21(0.63)$ & $4.21(0.79)$ & ns \\
\hline Number of deployments & $2.07(1.18)$ & $2.29(1.24)$ & ns \\
\hline \multicolumn{4}{|l|}{ STAXI-2 } \\
\hline State Anger & $24.29(11.45)$ & $15.21(0.79)$ & $t(1,54)=4.18, P<.001$ \\
\hline Trait Anger & $22.71(6.92)$ & $12.07(2.49)$ & $t(1,54)=7.66, P<.001$ \\
\hline \multicolumn{4}{|l|}{ Aggression Questionnaire } \\
\hline Physical aggression & $30.11(7.62)$ & $18.46(4.55)$ & $t(1,54)=6.94, P<.001$ \\
\hline Verbal aggression & $15.54(3.99)$ & $11.36(1.42)$ & $t(1,54)=5.23, P<.001$ \\
\hline Anger & $24.46(5.43)$ & $11.18(2.45)$ & $t(1,54)=11.80, P<.001$ \\
\hline Hostility & $24.07(7.07)$ & $12.07(3.43)$ & $t(1,54)=8.08, P<.001$ \\
\hline
\end{tabular}

SD: standard deviation; ns: not significant.

Table 2

Behavioral data of the task.

\begin{tabular}{|c|c|c|c|c|c|c|c|c|c|}
\hline & \multicolumn{9}{|l|}{ IAPS rating } \\
\hline & \multicolumn{3}{|l|}{ Neutral } & \multicolumn{3}{|l|}{ Positive } & \multicolumn{3}{|l|}{ Negative } \\
\hline & Aggression (SD) & Control (SD) & $F$ & Aggression (SD) & Control (SD) & $F$ & Aggression (SD) & Control (SD) & $F$ \\
\hline \multicolumn{10}{|c|}{ Subjects' rating } \\
\hline Neutral & $0.77(0.16)$ & $0.86(0.13)$ & $5.43^{\mathrm{a}}$ & $0.25(0.17)$ & $0.15(0.14)$ & $5.93^{a}$ & $0.11(0.17)$ & $0.05(0.06)$ & 2.8 \\
\hline Positive & $0.09(0.09)$ & $0.07(0.11)$ & 0.01 & $0.70(0.17)$ & $0.84(0.14)$ & $10.21^{\mathrm{b}}$ & $0.02(0.03)$ & $0.01(0.02)$ & 0.52 \\
\hline Negative & $0.12(0.14)$ & $0.04(0.05)$ & $10.11^{\mathrm{b}}$ & $0.03(0.05)$ & $0.00(0.02)$ & $6.37^{\mathrm{a}}$ & $0.87(0.17)$ & $0.93(0.07)$ & 3.06 \\
\hline
\end{tabular}

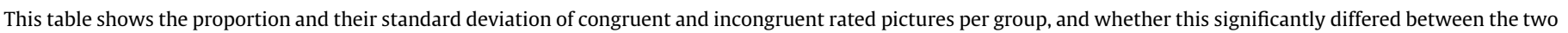
groups.

a Indicates significance at the .05 level.

b Indicates significance at the .01 level.

Table 3

Whole-brain activation within subjects during the negative and positive contrast.

\begin{tabular}{lllllll}
\hline Brain area & L/R & Peak value & $\mathrm{x}$ & $\mathrm{y}$ & $\mathrm{z}$ & $\mathrm{N}$ voxels \\
\hline Negative $>$ Neutral & & & & & & \\
Medial temporal & $\mathrm{R}$ & 8.41 & 52 & -52 & 10 & 1235 \\
Medial temporal & $\mathrm{L}$ & 8.28 & -46 & -60 & 14 & 1372 \\
Amygdala & $\mathrm{L}$ & 6.62 & -24 & -6 & -16 & 628 \\
Posterior cingulum & $\mathrm{L}$ & 5.69 & 0 & -50 & 26 & 1354 \\
Medial temporal & $\mathrm{R}$ & 5.35 & 56 & 2 & -16 & 219 \\
Hippocampus_L & $\mathrm{L}$ & 5.16 & -6 & -2 & -16 & 706 \\
Medial temporal pole & $\mathrm{R}$ & 4.69 & 46 & 16 & -26 & 216 \\
Superior medial frontal cortex & $\mathrm{R}$ & 4.39 & 2 & 58 & 22 & 430 \\
Medial orbitofrontal cortex & $\mathrm{L}$ & 4.27 & 0 & 56 & -2 & 161 \\
Superior temporal pole & $\mathrm{L}$ & 3.84 & -40 & 20 & -28 & 67 \\
Inferior parietal cortex & $\mathrm{R}$ & -4.20 & 50 & -46 & 46 & 189 \\
Medial frontal cortex & $\mathrm{R}$ & -3.80 & 42 & 46 & 18 & 154 \\
Inferior parietal cortex & $\mathrm{R}$ & -3.71 & 50 & -54 & 42 & 144 \\
Positive $>$ Neutral & & & & & & \\
Anterior cingulum & $\mathrm{L}$ & 6.45 & 2 & 6 & 16 & 5579 \\
Medial temporal & $\mathrm{L}$ & 6.21 & -44 & -64 & 16 & 894 \\
Medial temporal & $\mathrm{R}$ & 5.98 & 48 & -58 & 10 & 490 \\
Medial temporal & $\mathrm{L}$ & 4.39 & -58 & -4 & -16 & 99 \\
Caudate nucleus & $\mathrm{L}$ & 3.96 & -6 & 18 & -6 & 65 \\
Superior temporal pole & $\mathrm{L}$ & 3.82 & -38 & 22 & -28 & 46 \\
Superior frontal cortex & $\mathrm{L}$ & 3.67 & -18 & 36 & 50 & 58 \\
Medial temporal & $\mathrm{R}$ & 3.65 & 60 & 0 & -18 & 54 \\
Amygdala & $\mathrm{L}$ & 3.58 & -22 & -2 & -18 & 55 \\
Hippocampus & $\mathrm{L}$ & 3.54 & -24 & -14 & -18 & 62 \\
Superior temporal pole & $\mathrm{R}$ & 3.45 & 46 & 20 & -28 & 43 \\
\hline
\end{tabular}

Clusters $k>20$ were reported.

stronger activation was found in the supplemental motor area, frontal cortex, inferior parietal cortex and the anterior cingulum. All differences are depicted in Table 4 and Fig. 3.

\subsubsection{ROI analyses}

Activation of the basolateral and the centromedial amygdala and the dorsal ACC did not differ between the two groups (all $P$ 's $>.10$, uncorrected).

\subsubsection{PPI analyses}

PPI analyses using the BLA and the CMA as seed regions, did not reveal differences in task-related changes in functional connectivity, both within and between the two groups, using a threshold of $P<.001$, uncorrected.

PPI analyses using the left and right dACC as seed regions, revealed stronger connectivity with the amygdala in the Aggression group compared to the control group during the Negative minus Neutral contrast, using a threshold of $P<.001$, uncorrected. The Positive minus Neutral contrast revealed diminished connectivity with the (orbito)frontal cortex in the Aggression group. All differences are shown in Table 5.

\section{Discussion}

In this study we examined whether veterans with anger and aggression problems show different brain activation and functional connectivity in response to general, non-facial emotional stimuli. To test this, positive, negative and neutral pictures were shown during an fMRI scan. It was found that the groups showed no differences either on the negative minus neutral contrast or the positive minus neutral contrast. However, a main effect of picture presentation was found, with stronger activation in motor areas and the parietal cortex evoked by stimuli in the Aggression group compared to the Control group.

These group differences in the parietal cortex point towards increased attention to the stimuli in general, regardless of their valence in the Aggression group, possibly due to the context in which every stimulus had the potential to be negative. Indeed, attentional problems have been reported in aggression and emotion regulation before [38,39]. In individuals reporting dysfunctional anger, differences in levels of oscillatory EEG activity were found that were interpreted as a chronic hypervigilant state [38], which may lead to an overreaction to non-harmful situations. The increased cue reactivity as found in the current study might 

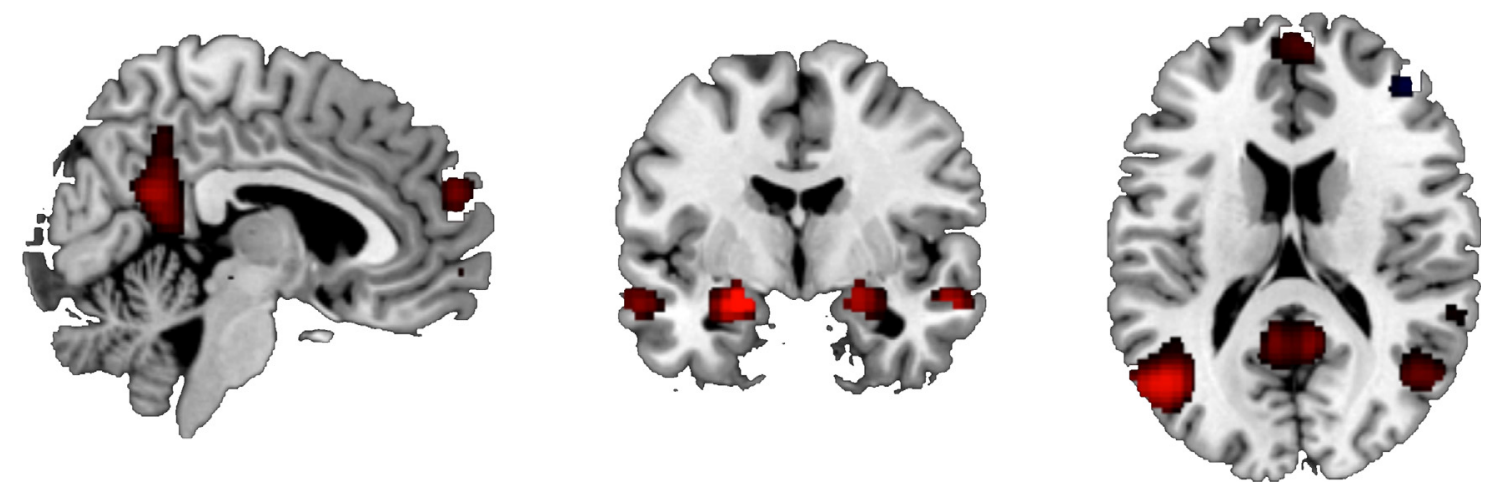

Fig. 2. Brain activation during the Negative minus Neutral contrast, showing the task effect. $P<.05$, FWE-corrected.

Table 4

Stronger brain activity during all stimuli in the Aggression group compared to the control group.

\begin{tabular}{llllllr}
\hline Brain area & $\mathrm{L} / \mathrm{R}$ & Peak value & $\mathrm{x}$ & $\mathrm{y}$ & $\mathrm{z}$ & $\mathrm{N}$ voxels \\
\hline Precentral gyrus & $\mathrm{L}$ & 7.3554 & -40 & -4 & 56 & 153 \\
Medial frontal cortex & $\mathrm{R}$ & 6.8658 & 46 & 4 & 54 & 147 \\
Superior frontal cortex & $\mathrm{R}$ & 6.638 & 20 & 32 & 52 & 101 \\
Precentral gyrus & $\mathrm{R}$ & 6.6167 & 44 & -8 & 42 & 394 \\
Caudate nucleus & $\mathrm{L}$ & 6.3178 & -14 & 2 & 18 & 94 \\
Supplemental motor area & $\mathrm{R}$ & 6.2 & 12 & 2 & 68 & 77 \\
Inferior parietal cortex & $\mathrm{R}$ & 6.134 & 34 & -52 & 50 & 195 \\
Supplemental motor area & $\mathrm{L}$ & 6.1327 & 0 & 12 & 64 & 71 \\
Medial frontal cortex & $\mathrm{R}$ & 5.9376 & 44 & 38 & 20 & 110 \\
Putamen & $\mathrm{R}$ & 5.8881 & 28 & -12 & 4 & 36 \\
Cuneus & $\mathrm{L}$ & 5.8793 & -8 & -84 & 32 & 27 \\
Medial temporal & $\mathrm{R}$ & 5.8435 & 50 & -44 & 0 & 144 \\
Paracentral lobule & $\mathrm{L}$ & 5.6892 & -18 & -30 & 64 & 43 \\
Mid cingulum & $\mathrm{R}$ & 5.6208 & 10 & 20 & 36 & 22 \\
Supramarginal gyrus & $\mathrm{R}$ & 5.6199 & 50 & -40 & 46 & 145 \\
Inferior temporal cortex & $\mathrm{R}$ & 5.6061 & 56 & -34 & -16 & 21 \\
Precentral gyrus & $\mathrm{R}$ & 5.5744 & 24 & -22 & 58 & 127 \\
Postcentral gyrus & $\mathrm{R}$ & 5.5012 & 44 & -12 & 28 & 86 \\
Precentral gyrus & $\mathrm{L}$ & 5.3306 & -28 & -18 & 64 & 25 \\
Caudate nucleus & $\mathrm{L}$ & 5.2511 & -10 & -6 & 18 & 60 \\
Medial temporal & $\mathrm{R}$ & 5.2364 & 54 & -40 & -8 & 77 \\
Medial frontal cortex & $\mathrm{R}$ & 5.2077 & 48 & 34 & 36 & 23 \\
Paracentral lobule & $\mathrm{L}$ & 5.2073 & -16 & -30 & 68 & 42 \\
Medial temporal & $\mathrm{R}$ & 5.1408 & 46 & -44 & 8 & 52 \\
Precentral gyrus & $\mathrm{R}$ & 5.0847 & 32 & -28 & 68 & 21 \\
Precentral gyrus & $\mathrm{R}$ & 4.9903 & 36 & -26 & 58 & 21 \\
Anterior cingulum & $\mathrm{L}$ & 4.9282 & -2 & 40 & 16 & 21 \\
\hline Activatorclusters & & & & & &
\end{tabular}

Activation clusters are reported when $k>20$.

also reflect a general heightened arousal level. In line with this possibility, in an earlier study we showed that military veterans with aggression had a heightened startle response [40].

Furthermore, stronger activation in motor areas points was found in the Aggression group. This could be related to impulsivity and reduced inhibition [41], which are strongly associated with aggression [42]. The concept of impulsivity refers to the tendency to act quickly, without thinking or planning. Furthermore, individuals with higher trait anger show impaired response inhibition in a Go/NoGo task [43], and individuals with higher trait aggression showed a combination of reduced orienting but enhanced preparation for action in a threat-anticipation task [44]. The motor-related activation in the Aggression group might therefore be related to impulsiveness and preparation to respond quickly, prior to proper stimulus discrimination, although we do not have direct measures of this.

Using the dACC as a seed region, differences in functional connectivity between the two groups were found. During the viewing of negative pictures, the Anger group show stronger connectivity between the left amygdala and both the left and right
dACC. This is similar to a previous finding in which participants with an anxiety disorder showed increased dACC-amygdala connectivity during the viewing of negative facial stimuli [45]. Because the dACC is involved with responses to stimuli requiring control or adaptation [46], this effect might indicate a tendency to attend to negative stimuli and respond to them via upregulation of their emotional processing [45]. Furthermore, the diminished connectivity of the dACC with frontal areas as observed in the Aggression group, might point towards reduced attention to positive stimuli or their evaluation $[23,47]$. The hemispheric effect is hard to interpret, however, a systematic review reported that the left amygdala often shows stronger activation compared to the right amygdala [48]. Taken together, the connectivity results therefore suggest a negative bias in attentional processes that could skew the perception of situations as threatening. We note however that these results were not generally whole-brain significant. Future studies need to confirm the valildy of our findings and interpretations.

The behavioral data in the current study show that the participants in the Aggression group were more likely to rate the positive pictures as neutral or negative, and the neutral pictures more likely as negative. This is in line with the finding that people with anger regulation deficits show a hostile attribution bias. According to the hostile attribution bias, ambiguous situations are more easily interpreted as hostile [49]. In individuals with aggression problems it is often reported that they tend to interpret cues and situations as hostile [50], from which dysfunctional behavior could follow. This tendency could be related to the findings showing abnormal connectivity discussed above: If individuals are highly sensitive to negative information but fail to pay attention to positive information, this would be expected to negatively bias their interpretations of situations.

The finding that amygdala activation did not differ between the two groups, is not in line with previous studies $[15,16]$, possibly due to the use of different stimuli or the military versus nonmilitary populations. In the previous studies, heightened amygdala activation was found in Intermittent Explosive Disorder in response to angry faces. Also in an anger-inducing experiment, stronger activation of the amygdala has been reported [51]. Furthermore, individuals scoring high on trait anger, show a stronger bias for angry faces [52]. These studies evoked negative emotions with different stimuli compared to the current study. In the current study, general, non-facial, emotional stimuli were used, and although the task did reveal amygdala reactivity, this reactivity did not differ between the two groups. Facial expressions are rather homogeneous in comparison to IAPS pictures, and might represent danger more consistently than non-facial stimuli [24]. Affective biases in individuals with dysregulated aggression might mainly be observed when social cues are presented. Thus, the current task might induce different emotions compared to previous studies, 

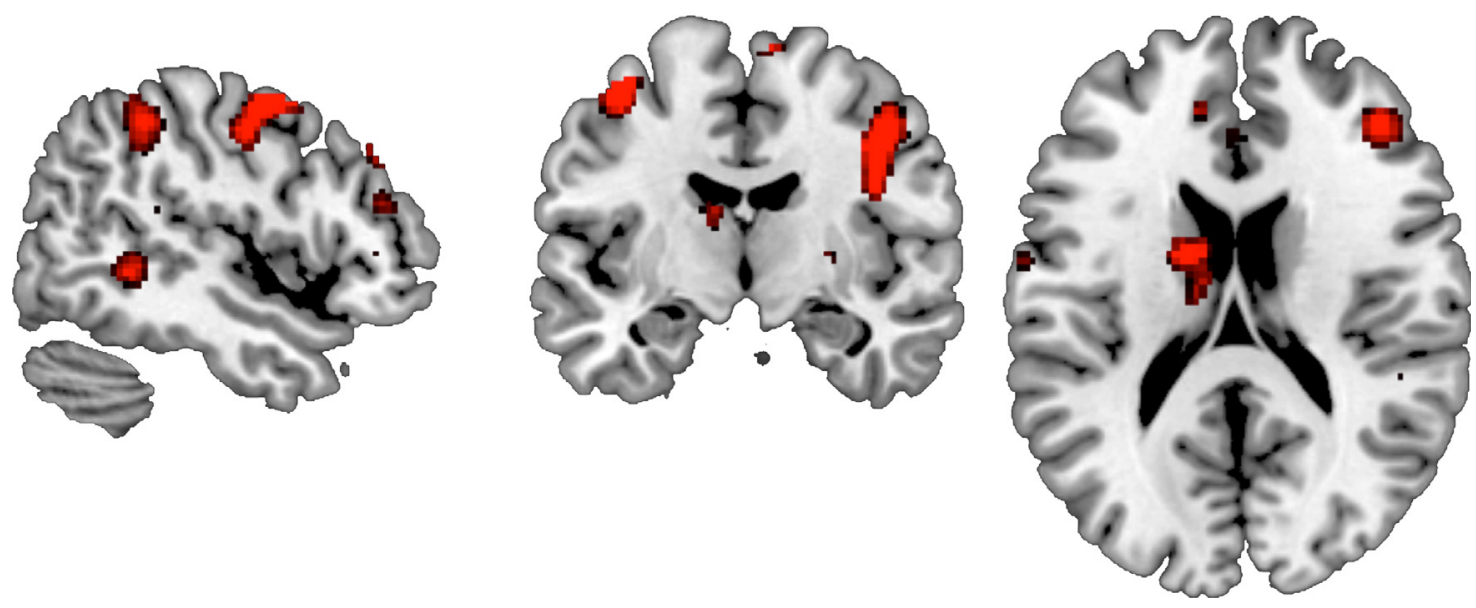

Fig. 3. Stronger brain activation in the Aggression group during the viewing of the pictures, regardless of category. $P<.05$, FWE-corrected.

Table 5

Group differences in dACC coupling during negative versus neutral picture viewing.

\begin{tabular}{|c|c|c|c|c|c|c|c|c|}
\hline Seed region & Brain area & $\mathrm{L} / \mathrm{R}$ & Peak value & $\mathrm{x}$ & $\mathrm{y}$ & $\mathrm{z}$ & $\mathrm{N}$ voxels & Whole-brain $P$ \\
\hline \multicolumn{9}{|c|}{ Negative minus Neutral contrast } \\
\hline \multirow[t]{7}{*}{ Left dACC } & Transverse temporal gyrus & $\mathrm{L}$ & 4.90 & -34 & -32 & 10 & 152 & .11 \\
\hline & Frontal Superior cortex & $\mathrm{R}$ & 4.36 & 32 & 4 & 80 & 22 & .87 \\
\hline & Amygdala & $\mathrm{L}$ & 4.30 & -22 & -10 & -12 & 32 & .72 \\
\hline & Parahippocampal area & $\mathrm{R}$ & 3.98 & 16 & -18 & -20 & 36 & .66 \\
\hline & Putamen & $\mathrm{R}$ & 3.90 & 34 & -2 & 6 & 28 & .77 \\
\hline & Rolandic operculum & $\mathrm{R}$ & 3.81 & 46 & -2 & 14 & 28 & .77 \\
\hline & Hippocampus & $\mathrm{L}$ & 3.68 & -26 & -6 & -18 & 33 & .71 \\
\hline \multirow[t]{7}{*}{ Right dACC } & Thalamus & $\mathrm{L}$ & 4.61 & -20 & -20 & 12 & 77 & .29 \\
\hline & Inferior frontal gyrus & $\mathrm{R}$ & 4.05 & 2 & 58 & -24 & 26 & .70 \\
\hline & Amygdala & $\mathrm{L}$ & 3.93 & -20 & 2 & -22 & 32 & .70 \\
\hline & Transverse temporal gyrus & $\mathrm{L}$ & 3.90 & -34 & -30 & 10 & 29 & .74 \\
\hline & Putamen & $\mathrm{L}$ & 3.74 & -26 & -24 & 8 & 56 & .43 \\
\hline & Hippocampus & $\mathrm{L}$ & 3.59 & -22 & -14 & -12 & 27 & .78 \\
\hline & Cuneus & $\mathrm{L}$ & -3.64 & -6 & -94 & 28 & 33 & .69 \\
\hline \multicolumn{9}{|c|}{ Positive minus Neutral contrast } \\
\hline \multirow[t]{15}{*}{ Left dACC } & Mid orbitofrontal cortex & $\mathrm{R}$ & -3.56 & 4 & 70 & -14 & 35 & .66 \\
\hline & Posterior cingulum & $\mathrm{R}$ & -3.58 & 6 & -44 & 28 & 56 & .43 \\
\hline & Medial frontal cortex & $\mathrm{R}$ & -3.68 & 40 & 52 & 20 & 92 & .22 \\
\hline & Medial frontal cortex & $\mathrm{R}$ & -3.85 & 34 & 36 & 46 & 43 & .57 \\
\hline & Medial temporal cortex & $\mathrm{R}$ & -3.91 & 58 & -12 & -22 & 50 & .49 \\
\hline & Medial frontal cortex & $\mathrm{R}$ & -4.30 & 48 & 54 & 10 & 255 & $.039 *$ \\
\hline & Posterior cingulum & $\mathrm{R}$ & -4.25 & 4 & -34 & 22 & 112 & .17 \\
\hline & Inferior frontal gyrus & $\mathrm{L}$ & -4.28 & -6 & 74 & -32 & 27 & .78 \\
\hline & Medial frontal cortex & $\mathrm{R}$ & -4.50 & 46 & 66 & 26 & 46 & .54 \\
\hline & Medial frontal cortex & $\mathrm{R}$ & -4.74 & 48 & 32 & 32 & 123 & .15 \\
\hline & Superior frontal cortex & $\mathrm{R}$ & -4.79 & 32 & 62 & 14 & 173 & .081 \\
\hline & Precentral gyrus & $\mathrm{L}$ & 6.06 & -44 & -10 & 82 & 85 & .26 \\
\hline & Postcentral gyrus & $\mathrm{L}$ & 4.80 & -60 & -14 & 54 & 87 & .24 \\
\hline & Inferior temporal cortex & $\mathrm{L}$ & 4.12 & -70 & -24 & -24 & 42 & .58 \\
\hline & Superior frontal cortex & $\mathrm{L}$ & 3.85 & -38 & 52 & 46 & 22 & .85 \\
\hline \multirow[t]{7}{*}{ Right dACC } & Inferior orbitofrontal cortex & $\mathrm{R}$ & -4.17 & 32 & 36 & -6 & 26 & .96 \\
\hline & Medial occipital lobe & $\mathrm{R}$ & 5.08 & 64 & -92 & 32 & 22 & .98 \\
\hline & Inferior temporal cortex & $\mathrm{L}$ & 4.45 & -66 & -26 & -24 & 59 & .69 \\
\hline & Medial occipital lobe & $\mathrm{R}$ & 4.21 & 64 & -94 & 32 & 32 & .92 \\
\hline & Orbitofrontal cortex & $\mathrm{L}$ & 3.65 & -50 & 48 & -28 & 30 & .93 \\
\hline & Postcentral gyrus & $\mathrm{L}$ & 3.76 & -36 & -22 & 30 & 37 & .88 \\
\hline & Inferior parietal cortex & $\mathrm{R}$ & 3.58 & 70 & -48 & 54 & 22 & .98 \\
\hline
\end{tabular}

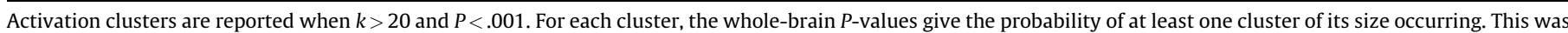
determined by permutation tests of the beta maps of the given contrast, in which group membership was randomly permuted on each of 1000 iterations. ${ }^{*} p=0.05$.

which do not distinguish the Aggression group from the control group.

A limitation of the current study is that the task we used does not actively require regulation of emotions. It remains unknown whether participants used strategies in order to regulate or suppress evoked emotions and whether this differed between the two groups. In future studies, it might be relevant to study emotion regulation instead of a passive viewing task. Furthermore, in this study only military veterans were compared; therefore, the effects of military training and deployment cannot be excluded. For example, brain activation of combat veterans with PTSD was only different compared to civilian controls and not compared to combat controls [21]. The common military training and experience may have diminished symptom-related group differences. 
Also, the duration of the problems as well as the treatment and/or medication that the participants were receiving was not taken into account in the analyses. Furthermore, the current sample size is limited and only male veterans were included. The $8-\mathrm{mm}$ smoothing kernel and the voxel size of $4 \mathrm{~mm}$ used in the current study might have limited detection of group differences in the PPI analyses using parcellations of the amygdala. However, in studies using similar analyses, differences were detected [53,54], indicating that subdivisions of the amygdala are indeed sufficiently parcellated using this smoothing method. Another limitation is that the stimuli were presented in a pseudo-random order, thus participants could not predict the valence of the stimuli. This may have resulted in effects related to potentially threatening or negative stimuli, instead of reactions actual negative stimuli. In future studies, it would be interesting to compare trials on which participants can versus cannot predict the valence of the upcoming stimulus, providing potentially interesting comparisons involving processes such as vigilance, uncertainity and reactivity.

In conclusion, the findings in the current study indicate a valence-aspecific increase in arousal and impulsivity in veterans with impulsive aggression in response to non-facial emotional stimuli. Furthermore, effects on functional connectivity involving the dACC, amygdala and medial prefrontal cortex point towards attentional abnormalities involving positive and negative stimuli. Impulsive aggression may emerge from a combination of negative biases in attention and interpretation, the consequences of which are exacerbated by impulsivity. These findings may provide targets for interventions, for example neurostimulation or biofeedback methods to decrease impulsivity and hypervigilance.

\section{Funding}

This work has been financially supported by the Dutch Ministry of Defense.

\section{Disclosure of interest}

The authors declare that they have no competing interest.

\section{References}

[1] Fear NT, Jones M, Murphy D, Hull L, Iversen AC, Coker B, et al. What are the consequences of deployment to Iraq and Afghanistan on the mental health of the UK armed forces? A cohort study. Lancet 2010;375:1783-97. http:// dx.doi.org/10.1016/S0140-6736(10)60672-1.

[2] Reijnen A, Rademaker AR, Vermetten E, Geuze E. Prevalence of mental health symptoms in Dutch military personnel returning from deployment to Afghanistan: a 2-year longitudinal analysis. Eur Psychiatry 2015;30:341-6. http://dx.doi.org/10.1016/j.eurpsy.2014.05.003.

[3] Heesink L, Rademaker A, Vermetten E, Geuze E, Kleber R. Longitudinal measures of hostility in deployed military personnel. Psychiatry Res 2015;229:479-84. http://dx.doi.org/10.1016/j.psychres.2015.05.082.

[4] Anderson CA, Bushman BJ. Human aggression. Annu Rev Psychol 2002;53:2751. http://dx.doi.org/10.1016/0191-8869(94)90294-1.

[5] Newby JM, McKinnon A, Kuyken W, Gilbody S, Dalgleish T. Systematic review and meta-analysis of transdiagnostic psychological treatments for anxiety and depressive disorders in adulthood. Clin Psychol Rev 2015;40:91-110. http:// dx.doi.org/10.1016/j.cpr.2015.06.002.

[6] Sukhodolsky DG, Smith SD, McCauley SA, Ibrahim K, Piasecka JB. Behavioral interventions for anger, irritability, and aggression in children and adolescents. J Child Adolesc Psychopharmacol 2016;26:58-64. http://dx.doi.org/10.1089/ cap.2015.0120.

[7] Davidson RJ, Putnam KM, Larson CL. Dysfunction in the neural circuitry of emotion regulation-a possible prelude to violence. Science 2000;289:591-4.

[8] Etkin A, Büchel C, Gross JJ. The neural bases of emotion regulation. Nat Rev Neurosci 2015;16. http://dx.doi.org/10.1038/nrn4044.

[9] Janak PH, Tye KM. From circuits to behaviour in the amygdala. Nature 2015;517:284-92. http://dx.doi.org/10.1038/nature14188.

[10] Hrybouski S, Aghamohammadi-Sereshki A, Madan CR, Shafer AT, Baron CA, Seres $\mathrm{P}$, et al. Amygdala subnuclei response and connectivity during emotional processing. Neuroimage 2016;133:98-110. http://dx.doi.org/10.1016/j.neuroimage.2016.02.056.

[11] Murray EA. The amygdala, reward and emotion. Trends Cogn Sci 2007;11:489-97. http://dx.doi.org/10.1016/j.tics.2007.08.013.
[12] Balleine BW, Killcross S. Parallel incentive processing: an integrated view of amygdala function. Trends Neurosci 2006;29:272-9. http://dx.doi.org/ 10.1016/j.tins.2006.03.002.

[13] Baxter MG, Murray EA. The amygdala and reward. Nat Rev Neurosci 2002;3:563-73. http://dx.doi.org/10.1038/nrn875.

[14] Hermans EJ, Henckens MJAG, Roelofs K, Fernández G. Fear bradycardia and activation of the human periaqueductal grey. Neuroimage 2013;66:278-87. http://dx.doi.org/10.1016/j.neuroimage.2012.10.063.

[15] Coccaro EF, McCloskey MS, Fitzgerald DA, Phan KL. Amygdala and orbitofrontal reactivity to social threat in individuals with impulsive aggression. Biol Psychiatry 2007;62:168-78. http://dx.doi.org/10.1016/j.biopsych.2006.08.024.

[16] McCloskey MS, Phan KL, Angstadt M, Fettich KC, Keedy S, Coccaro EF. Amygdala hyperactivation to angry faces in intermittent explosive disorder. J Psychiatr Res 2016;79:34-41. http://dx.doi.org/10.1016/j.jpsychires.2016. 04.006 .

[17] Best M, Williams JM, Coccaro EF. Evidence for a dysfunctional prefrontal circuit in patients with an impulsive aggressive disorder. Proc Natl Acad Sci U S A 2002;99:8448-53. http://dx.doi.org/10.1073/pnas.112604099.

[18] Adams DB. Brain mechanisms of aggressive behavior: an updated review. Neurosci Biobehav Rev 2006;30:304-18. http://dx.doi.org/10.1016/j.neubiorev.2005.09.004.

[19] Jakupcak M, Conybeare D, Phelps L, Hunt S, Holmes HA, Felker B, et al. Anger, hostility, and aggression among Iraq and Afghanistan War veterans reporting PTSD and subthreshold PTSD. J Trauma Stress 2007;20:945-54. http:// dx.doi.org/10.1002/jts.20258.

[20] Taft CT, Vogt DS, Marshall AD, Panuzio J, Niles BL. Aggression among combat veterans: relationships with combat exposure and symptoms of posttraumatic stress disorder, dysphoria, and anxiety. J Trauma Stress 2007;20:135-45. http://dx.doi.org/10.1002/jts.20197.

[21] van Rooij SJH, Rademaker AR, Kennis M, Vink M, Kahn RS, Geuze E. Neural correlates of trauma-unrelated emotional processing in war veterans with PTSD. Psychol Med 2015;45:575-87. http://dx.doi.org/10.1017/ S0033291714001706.

[22] van Rooij SJH, Kennis M, Vink M, Geuze E. Predicting treatment outcome in PTSD: a longitudinal functional MRI Study on trauma-unrelated emotional processing. Neuropsychopharmacology 2016;41:1156-65. http://dx.doi.org/ 10.1038/npp.2015.257.

[23] Etkin A, Egner T, Kalisch R. Emotional processing in anterior cingulate and medial prefrontal cortex. Trends Cogn Sci 2011;15:85-93. http://dx.doi.org/ 10.1016/j.tics.2010.11.004.

[24] Hariri AR, Tessitore A, Mattay VS, Fera F, Weinberger DR. The amygdala response to emotional stimuli: a comparison of faces and scenes. Neuroimage $2002 ; 17: 317-23$

[25] Coccaro EF. Intermittent explosive disorder as a disorder of impulsive aggression for DSM-5. Am J Psychiatry 2012;169:577-88. http://dx.doi.org/10.1176/ appi.ajp.2012.11081259.

[26] Van Vliet IM, Leroy H, Van Megen HJGM. MINI International Neuropsychiatric Interview (M.I.N.I.), Nederlandse versie 5.0.0; 2000.

[27] Hovens JE, Rodenburg JJ, Lievaart M. STAXI-2: Vragenlijst over boosheid [Manual of the Dutch Version of the State Trait Anger Expression Inventory (STAXI-2)]. Hogrefe; 2015. http://dx.doi.org/10.13140/2.1.1101.7926.

[28] Spielberger CD. STAXI-2. State-Trait Anger expression inventory. Psychological Assessment Resources. Florida: Lutz; 1999. p. 1999.

[29] Meesters C, Muris P, Bosma H, Schouten E, Beuving S. Psychometric evaluation of the Dutch version of the Aggression Questionnaire. Behav Res Ther 1996;34:839-43. http://dx.doi.org/10.1016/0005-7967(96)00065-4.

[30] Buss AH, Perry M. The aggression questionnaire. J Pers Soc Psychol 1992;63:452-9.

[31] Vink M, Derks JM, Hoogendam JM, Hillegers M, Kahn RS. Functional differences in emotion processing during adolescence and early adulthood. Neuroimage 2014;91:70-6. http://dx.doi.org/10.1016/j.neuroimage.2014.01.035.

[32] Lang PJ, Bradley MM, Cuthbert BN. International Affective Picture System (IAPS): technical manual and affective ratings. NIMH Cent Study Emot Atten 1997;39-58. http://dx.doi.org/10.1027/0269-8803/a000147.

[33] Gladwin TE, Vink M, Mars RB. A landscape-based cluster analysis using recursive search instead of a threshold parameter. MethodsX 2016;3:47782. http://dx.doi.org/10.1016/j.mex.2016.06.002.

[34] Eickhoff SB, Paus T, Caspers S, Grosbras M-H, Evans AC, Zilles K, et al. Assignment of functional activations to probabilistic cytoarchitectonic areas revisited. Neuroimage 2007;36:511-21. http://dx.doi.org/10.1016/j.neuroimage. 2007.03.060.

[35] O'Reilly JX, Woolrich MW, Behrens TEJ, Smith SM, Johansen-Berg H. Tools of the trade: psychophysiological interactions and functional connectivity. Soc Cogn Affect Neurosci 2012;7:604-9. http://dx.doi.org/10.1093/scan/ nss055.

[36] Lieberman MD, Cunningham WA. Type I and Type II error concerns in fMRI research: re-balancing the scale. Soc Cogn Affect Neurosci 2009;4:423-8. http://dx.doi.org/10.1093/scan/nsp052.

[37] Eklund A, Nichols TE, Knutsson H. Cluster failure: why fMRI inferences for spatial extent have inflated false-positive rates. Proc Natl Acad Sci U S A 2016;113:7900-5. http://dx.doi.org/10.1073/pnas.1602413113.

[38] Jaworska N, Berrigan L, Fisher D, Ahmed AG, Gray J, Bradford J, et al. A pilot study of electrocortical activity in dysfunctional anger: decreased frontocortical activation, impaired attention control, and diminished behavioral inhibition. Aggress Behav 2012;38:469-80. http://dx.doi.org/10.1002/ ab.21449. 
[39] Ochsner KN, Gross JJ. The cognitive control of emotion. Trends Cogn Sci 2005;9:242-9.

[40] Heesink L, Kleber R, Häfner M, van Bedaf L, Eekhout I, Geuze E. Anger and aggression problems in veterans are associated with an increased acoustic startle reflex. Biol Psychol 2016. http://dx.doi.org/10.1016/j.biopsycho.2016.12.004.

[41] Bari A, Robbins TW. Inhibition and impulsivity: behavioral and neural basis of response control. Prog Neurobiol 2013;108:44-79. http://dx.doi.org/10.1016 j.pneurobio.2013.06.005.

[42] Ramirez JM, Andreu JM. Aggression, and some related psychological constructs (anger, hostility, and impulsivity); some comments from a research project. Neurosci Biobehav Rev 2006;30:276-91. http://dx.doi.org/10.1016/ j.neubiorev.2005.04.015.

[43] Pawliczek CM, Derntl B, Kellermann T, Kohn N, Gur RC, Habel U. Inhibitory control and trait aggression: neural and behavioral insights using the emotional stop signal task. Neuroimage 2013;79:264-74. http://dx.doi.org/ 10.1016/j.neuroimage.2013.04.104.

[44] Gladwin TE, Hashemi MM, van Ast V, Roelofs K. Ready and waiting: freezing as active action preparation under threat. Neurosci Lett 2016;619:182-8. http:/| dx.doi.org/10.1016/j.neulet.2016.03.027.

[45] Robinson OJ, Krimsky M, Lieberman L, Allen P, Vytal K, Grillon C. The dorsal medial prefrontal (anterior cingulate) cortex-amygdala aversive amplification circuit in unmedicated generalised and social anxiety disorders: an observational study. Lancet Psychiatry 2014;1:294-302. http://dx.doi.org/10.1016/ S2215-0366(14)70305-0.

[46] Bush G, Luu P, Posner MI. Cognitive and emotional influences in anterior cingulate cortex. Trends Cogn Sci 2000;4:215-22. http://dx.doi.org/10.1016/ $\underline{\text { S1364-6613(00)01483-2. }}$
[47] Kanske P, Heissler J, Schönfelder S, Bongers A, Wessa M. How to regulate emotion? Neural networks for reappraisal and distraction. Cereb Cortex 2011;21:1379-88. http://dx.doi.org/10.1093/cercor/bhq216.

[48] Baas D, Aleman A, Kahn RS. Lateralization of amygdala activation: a systematic review of functional neuroimaging studies. Brain Res Rev 2004;45:96-103. http://dx.doi.org/10.1016/j.brainresrev.2004.02.004.

[49] Wilkowski BM, Robinson MD. The cognitive basis of trait anger and reactive aggression: an integrative analysis. Pers Soc Psychol Rev 2008;12:3-21. http:// dx.doi.org/10.1177/1088868307309874.

[50] Schönenberg M, Jusyte A. Investigation of the hostile attribution bias toward ambiguous facial cues in antisocial violent offenders. Eur Arch Psychiatry Clin Neurosci 2014;264:61-9. http://dx.doi.org/10.1007/s00406-013-0440-1.

[51] Dougherty DD, Rauch SL, Deckersbach T, Marci C, Loh R, Shin LM, et al. Ventromedial prefrontal cortex and amygdala dysfunction during an angerinduction positron emission tomography study in patients with major depressive disorder with anger attacks. Arch Gen Psychiatry 2004;61:795. http:// dx.doi.org/10.1001/archpsyc.61.8.795.

[52] Van Honk J, Tuiten A, de Haan E, Van den Hout M, Stam H. Attentional biases for angry faces: relationships to trait anger and anxiety. Cogn Emot 2001;15:279-97. http://dx.doi.org/10.1080/02699930126112.

[53] Yoder KJ, Porges EC, Decety J. Amygdala subnuclei connectivity in response to violence reveals unique influences of individual differences in psychopathic traits in a nonforensic sample. Hum Brain Mapp 2015;36:1417-28. http:// dx.doi.org/10.1002/hbm.22712.

[54] Stock J, Van den, Hortensius R, Sinke C, Goebel R, de Gelder B, et al. Personality traits predict brain activation and connectivity when witnessing a violent conflict. Sci Rep 2015;5:13779. http://dx.doi.org/10.1038/srep13779. 